\title{
High Effective of 14-Day High-Dose PPI- Bismuth-Containing Quadruple Therapy with Probiotics Supplement for Helicobacter Pylori Eradication: A Double Blinded-Randomized Placebo-Controlled Study
}

\author{
Piyakorn Poonyam¹, Peranart Chotivitayatarakorn", ${ }^{1,2}$ Ratha-Korn Vilaichone ${ }^{1,2,3 *}$
}

\begin{abstract}
Background: Helicobacter pylori (H. pylori) infection is important risk factors for chronic gastritis, peptic ulcer and gastric cancer. Bismuth-containing quadruple therapy has recently been the first-line regimen recommended in many European countries but has limited efficacy in ASEAN especially Thailand. This study was aim to evaluate efficacy of high dose PPI Bismuth-containing quadruple therapy with probiotics supplement for H. pylori eradication. Methods: In this double-blind randomized placebo-controlled study, H. pylori infected patients were randomized to receive 7-or 14-day high dose PPI- bismuth-containing quadruple therapy with or without probiotics supplement. Probiotic was $37.5 \mathrm{mg}$ Lactobacillus reuteri (Biogaia ${ }^{\circledR}$ ) in tablet twice daily. CYP2C19 genotyping and antibiotic susceptibility tests were also done. H. pylori eradication was defined as a negative $13 \mathrm{C}$-urea breath test at least 4 weeks after treatment. Results: 100 subjects were enrolled ( 72 females, 28 males, mean age=54 years). Antibiotic resistance was $15.6 \%$ for clarithromycin, $34.1 \%$ for metronidazole. CYP2C19 genotyping was performed in both group and revealed $13 \%, 50 \%$ and $37 \%$ for poor, intermediate and rapid metabolizers, respectively. Overall eradication rates of 7-day and 14-day regimens with probiotic were $68 \%$ and $96 \%$; $\mathrm{P}$ value $=0.027$. The eradication rate for all patients with poor and rapid metabolizers were $100 \%$ with 14-day regimen. 14-day regimen with probiotics can provide $100 \%$ eradication with clarithromycin resistance, metronidazole resistance or dual clarithromycin and metronidazole resistance group. Furthermore, the incidence of nausea and vomiting, abdominal discomfort, and bitter taste were significantly lower in patients with probiotics group compared with placebo $(6 \% \mathrm{vs} .26 \%, \mathrm{P}=0.002, \mathrm{OR}=0.126,95 \% \mathrm{CI}=0.03-0.53 ; 4 \% \mathrm{vs} .18 .0 \%, \mathrm{P}=0.017$, $\mathrm{OR}=0.155,95 \% \mathrm{CI}=0.03-0.81$ and $4 \% \mathrm{vs} .26 \%, \mathrm{P}=0.001, \mathrm{OR}=0.08,95 \% \mathrm{CI}=0.016-0.41$, respectively). Conclusions: The 14-day high dose PPI- bismuth-containing quadruple therapy with probiotic can provide an excellent cure rate for H. pylori infection as first line treatment irrespective of CYP2C19 and antibiotic resistance pattern. Adding probiotic also significantly reduced treatment-related adverse events and improve the patients' compliance.
\end{abstract}

Keywords: High-dose PPI- quadruple therapy- probiotics supplement- Helicobacter pylori

Asian Pac J Cancer Prev, 20 (9), 2859-2864

\section{Introduction}

Helicobacter pylori (H. pylori) is a well-known and proved organism which causes gastric inflammation, peptic ulcer disease (PUD), mucosa-associated lymphoid tissue (MALT) lymphoma and gastric cancer (Rauws and Tytgat, 1990; Bayerdorffer et al., 1995; Parasonet et al., 1991; van der Hulst et al., 1996; Aumpan et al., 2019). Thailand consensus for $H$. pylori management in 2015 suggested that standard triple therapy regimen had cure rate only $80 \%$ or less (Mahachai et al., 2016). The alternative first line treatment for $H$. pylori eradication in Thailand is 10 -day sequential therapy or 10-day concomitant therapy.
However, sequential regimen had complicated daily drug administration and concomitant regimen also associated with taking multiple medication tablets which all were consistent with poor patient compliance and increased adverse drug reactions. Thailand consensus also suggested that adding probiotics in regimen could improve patient adherence and might increase efficacy of eradication rate (Mahachai et al., 2016).

Bismuth-containing quadruple therapy has been recommended as first line treatment in European countries and the United States of America. However, there has limited of evidence about the cure rate for H. pylori eradication in ASEAN (Mahachai et al.,

${ }^{1}$ Gastroenterology Unit, ${ }^{2}$ Digestive Diseases Research Center (DRC), Thammasat University Hospital, ${ }^{3}$ Department of Medicine, Chulabhorn International College of Medicine (CICM) at Thammasat University, Pathumthani, Thailand. *For Correspondence: Vilaichone@hotmail.co.th 
2018). This study aim to investigate the cure rate of H. pylori eradication treatment with 7-day and 14-day Bismuth-containing quadruple therapy with probiotics (Biogaia Gastrus) for H. pylori eradication in Thai patients with non-ulcer dyspepsia. The results will be benefit for $H$. pylori treatment in whole ASEAN countries. CYP2C19 genotypes have an effect on pharmacokinetics and pharmacodynamics of proton pump inhibitor (PPI) which involved in changing gastric $\mathrm{pH}$ and effectiveness of $\mathrm{H}$. pylori eradication. Majority of CYP2C19 genotype in ASEAN patients was related to rapid and intermediate metabolizer (Srinarong et al., 2014). This study also conducted CYP2C19 genetic polymorphisms which could influence treatment outcome.

Lactobacillus reuteri (L. reuteri) is a gram-positive organism in Lactobacilli group which can change gastric environment from produce lactic acid and 3-hydroxypropionaldehyde (reuterin) which have antibiotic property against $H$. pylori infection (Gerrits et al., 2006). Furthermore, prior studies of $L$. reuteri suggested that this organism could reduce side-effects of $H$. pylori treatment regimen significantly such as abdominal pain, bloating and diarrhea (Dore et al., 2014; Dore et al., 2015; Francavilla et al., 2008).

\section{Materials and Methods}

\section{Patients}

Patients age more than 18 years who underwent upper GI endoscopy for evaluation of chronic dyspepsia were included. Patients with non-ulcer dyspepsia, defined as normal upper GI endoscopy or only mild gastritis, were included in the study. Those with a history of prior $H$. pylori eradication, currently receiving PPI, H2blocker, bismuth group or any kinds of antibiotics within 4 weeks before this study, receiving anticoagulants or NSAIDs, and other serious underlying diseases (eg. heart diseases, major illness, or cancers) were excluded. All participants were written informed consent including understanding and accepting objectives, protocols and treatment complications. This study is already approved by Thammasat University Hospital Ethic committee and was registered to the national clinical registry TCTR20190127003.

\section{The diagnosis of H. pylori infection}

4 biopsies from antrum of stomach were done during upper GI endoscopy for rapid urease test, H. pylori culture, histological examination, CYP2C19 genotype, Epsilometer test (E-test) or GenoType ${ }^{\circledR}$ HelicoDR. The positive $H$. pylori infection was defined as: positive H. pylori culture, or two positive tests (rapid urease test and histology). The CYP2C19 genotyping were demonstrated as: rapid metabolizer ( $\mathrm{RM})$, intermediate metabolizer (IM), or poor metabolizer (PM).

\section{Therapeutic regimens}

All patients were randomized into 4 groups by using a computer-generated list: (1) 7-day high dose PPI-bismuth-containing quadruple therapy with probiotics, (2) 7-day high dose PPI- bismuth-containing quadruple therapy with placebo, (3) 14-day high dose PPI-bismuthcontaining quadruple therapy with probiotics, or (4) 14-day high dose PPI- bismuth-containing quadruple therapy with placebo. High dose PPI- bismuth-containing quadruple therapy consisted of bismuth subsalicylate $1,048 \mathrm{mg}$ orally twice daily after meal, metronidazole $400 \mathrm{mg}$ orally 3-time a day after meal, tetracycline 500 mg orally 4-time a day after meal and dexlansoprazole 60 mg twice daily before meal. Probiotic was Lactobacillus reuteri gastrus (L. reuteri DSM17938 and L. reuteri ATCC PTA6475) in tablet (Biogaia gastrus ${ }^{\circledR}$ ) dosed $37.5 \mathrm{mg}$ twice daily after a meal, whereas placebo was exactly identical tablet without probiotics.

\section{Post-therapy follow-up}

13C-UBT was applied to assess H. pylori eradication in all individual after treatment for at least 4 weeks. Successful of treatment was defined as negative 13C-UBT. Pill count was done, and drug consumption greater than $90 \%$ was defined as well adherent. Personal interview with open-ended questions by questionnaire were used to assess adverse events. The likelihood side-effects listed in questionnaires were nausea, vomiting, skin rashes, bitter taste, abdominal discomfort, diarrhea, headache and palpitation. Therapy-related side effects were defined as new symptoms and worsening of pre-existing symptoms during the treatment period. Side effects severe enough to disrupt patients' activity from normal life and require hospitalizing were defined as serious events.

\section{Statistical analysis}

The eradication rate of treatment regimen was estimated to be more than $90 \%$. Treatment success was defined as a cure rate more than $95 \%$ (grade A) as described before (Graham et al., 2007), and failure as a cure rate of less than $90 \%$ per protocol. Chi-squared, Fisher's exact, and student's t-test were used to compare the demographic characteristics and frequencies of side-effects where appropriate. Statistic significant defined as P-value less than 0.05 . This study was approved by our local ethics committee, and was conducted according to good clinical practice guideline, as well as Declaration of Helsinki.

\section{Results}

Total of 100 patients were enrolled in this study, there were 72 females and 28 males which mean age of 54 years. The baseline demographic data were shown in table 1.

\section{Eradication of $H$. pylori infection}

Both intention-to-treat and per-protocol analyses results were similar because of no dropping out during study period. H. pylori eradication rates in 7-day regimen and 14-day regimen with probiotic were $68 \%$ and $96 \%$ respectively, $\mathrm{P}$ value $=0.027$ (Figure 1$)$.

Antibiotic susceptibility tests (Figure 2.) were performed in 68 strains (27 from E-test and 41 from GenoType ${ }^{\circledR}$ HelicoDR), which have been demonstrated in, $15.6 \%$ for clarithromycin, and $34.1 \%$ for metronidazole. Interestingly, there were no tetracycline and amoxicillin 


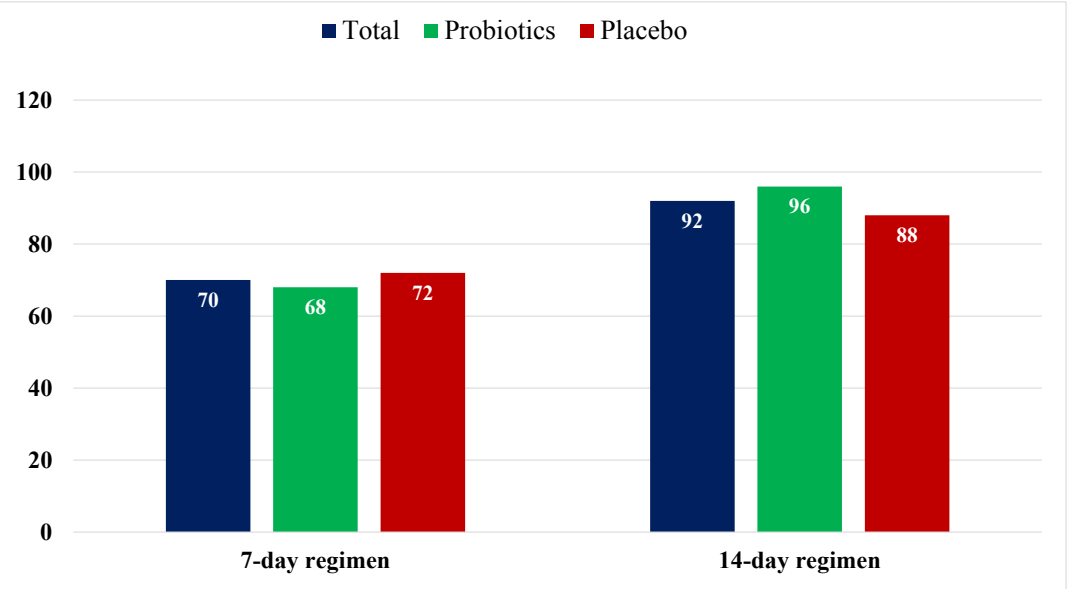

Figure 1. The Eradication Rates According to Treatment Regimens

Table 1. Baseline Demographic Data of All patients

\begin{tabular}{lccc}
\hline Characteristic data & $\begin{array}{c}\text { 7-day } \\
\text { regimen } \\
\mathrm{N}=50\end{array}$ & $\begin{array}{c}\text { 14-day } \\
\text { regimen } \\
\mathrm{N}=50\end{array}$ & P value \\
\hline Age (years) & 56 & 52 & - \\
Male (\%) & $17(34 \%)$ & $11(22 \%)$ & 0.181 \\
Underlying disease & & & \\
Diabetes & $2(4 \%)$ & $4(8 \%)$ & 0.40 \\
Dyslipidemia & $3(6 \%)$ & $9(18 \%)$ & 0.065 \\
Hypertension & $5(10 \%)$ & $12(24 \%)$ & 0.062 \\
Smoking & $2(4 \%)$ & $0(0 \%)$ & 0.153 \\
Alcohol consumption & $4(8 \%)$ & $4(8 \%)$ & 1.0 \\
\hline
\end{tabular}

resistance in this cohort. CYP2C19 genotyping was performed in both group and revealed $13 \%, 50 \%$ and $37 \%$ for poor, intermediate and rapid metabolizers, respectively
(Figure 3). 14-day regimen can provide eradication rate from $78.57 \%-100 \%$ in all CYP2C19 genotypes patients in our study (Table 2). Nevertheless, 14-day regimen with probiotics can provide $100 \%$ treatment with clarithromycin resistance, metronidazole resistance or both clarithromycin and metronidazole resistance group respectively (Table 3.)

\section{Adverse events}

Bitter taste, nausea and vomiting, black stool and abdominal discomfort are common adverse events in these regimens. All adverse events were demonstrated in Table 4. The incidence of nausea vomiting, abdominal discomfort, and bitter taste were significantly lower in patients with probiotics compared to placebo $(6 \% \mathrm{vs}$. $26 \%, \mathrm{P}=0.002, \mathrm{OR}=0.126,95 \% \mathrm{CI}=0.03-0.53 ; 4 \%$ vs. $18.0 \% \mathrm{P}=0.017, \mathrm{OR}=0.155,95 \% \mathrm{CI}=0.03-0.81$, and $4 \%$ vs. $26 \%, \mathrm{P}=0.001, \mathrm{OR}=0.08,95 \% \mathrm{CI}=0.016-0.41$,

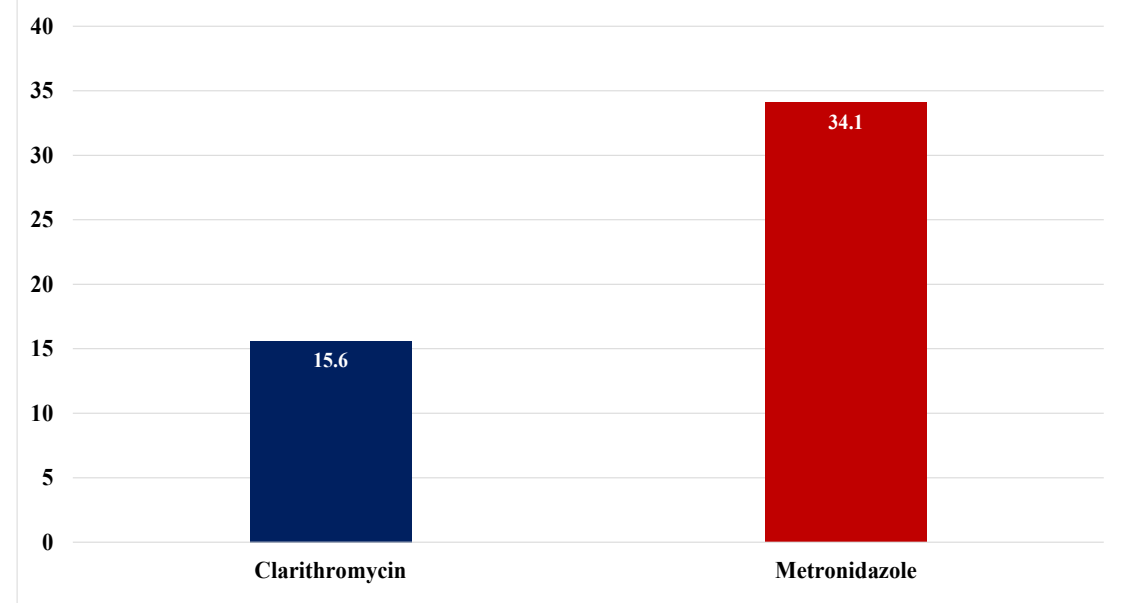

Figure 2. The Prevalence (\%) of Antibiotics Resistance Determined by E-test and Genotype HelicoDR

Table 2. CYP2C19 Genotype and Eradication Rates

\begin{tabular}{lcccc}
\hline $\begin{array}{l}\text { CYP2C19 genotype } \\
(\mathrm{N}=100)\end{array}$ & $\begin{array}{c}\text { 7-day plus probiotics } \\
(\mathrm{N}=25)\end{array}$ & $\begin{array}{c}\text { 7-day plus placebo } \\
(\mathrm{N}=25)\end{array}$ & $\begin{array}{c}\text { 14-day plus probiotics } \\
(\mathrm{N}=25)\end{array}$ & $\begin{array}{c}\text { 14-day plus placebo } \\
(\mathrm{N}=25)\end{array}$ \\
\hline PM $(\mathrm{N}=13 ; 13 \%)$ & $3(66.67 \%)$ & $3(100 \%)$ & $3(100 \%)$ & $4(100 \%)$ \\
IM No. $(\mathrm{N}=50 ; 50 \%)$ & $10(90 \%)$ & $11(81.81 \%)$ & $15(93.33 \%)$ & $14(78.57 \%)$ \\
RM No. $(\mathrm{N}=37 ; 37 \%)$ & $12(58.33 \%)$ & $11(72.72 \%)$ & $7(100 \%)$ & $7(100 \%)$ \\
\hline
\end{tabular}

*number in parentheses are eradication rates 


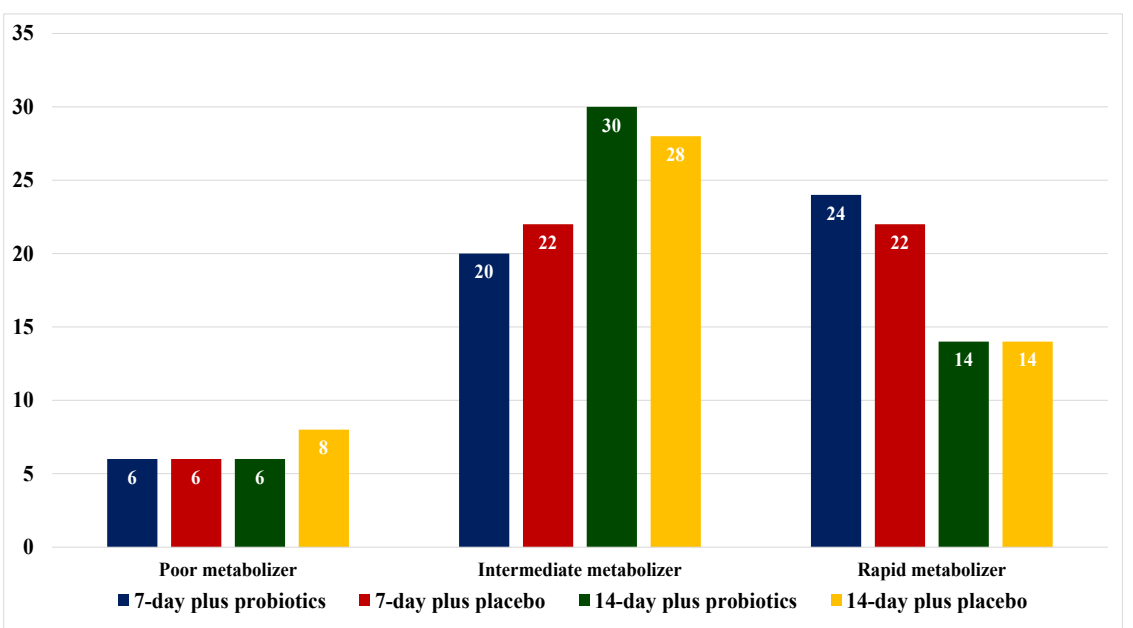

Figure 3. The Prevalence (\%) of CYP2C19 Genotype

Table 3. Antibiotic Resistance Pattern and Eradication Rates

\begin{tabular}{lcccc}
\hline Antibiotic resistance & 7-day plus probiotics & 7-day plus placebo & 14-day plus probiotics & 14-day plus placebo \\
\hline CH resistance $(\mathrm{N}=12)$ & $2 / 6(66.67 \%)$ & $2 / 3(33.33 \%)$ & $0 / 1(100 \%)$ & $0 / 2(100 \%)$ \\
MZ resistance $(\mathrm{N}=14)$ & $0 / 2(100 \%)$ & $2 / 4(50 \%)$ & $0 / 4(100 \%)$ & $1 / 4(75 \%)$ \\
$\mathrm{CH}$ and $\mathrm{MZ}$ resistance $(\mathrm{N}=4)$ & - & $0 / 1(100 \%)$ & $0 / 1(100 \%)$ & $0 / 2(100 \%)$ \\
\hline
\end{tabular}

*, number in parentheses are eradication rates

respectively).

\section{Discussion}

Many epidemiological and experimental studies were supported significant association between $H$. pylori infection and chronic gastritis, peptic ulcer disease, and gastric cancer (Vilaichone and Mahachai, 2001; Vilaichone et al., 2006; Ford et al., 2014: Mahachai et al., 2018). Prevalence of $H$. pylori infection is ranging from $20 \%$ in Malaysia, 21-54\% in Thailand, 31\% in Singapore, $>50 \%$ in Myanmar, Laos and Vietnam (Vilaichone et al., 2018). Gastric cancer is the fourth most common cancer worldwide and more than $70 \%$ of cases occurs in East Asia and developing countries. The treatment outcome are also grave because of advanced stage of presentations (Vilaichone et al., 2001; Vilaichone et al., 2006; Ford et al., 2014; Rahman et al., 2014). Nowadays, H. pylori eradication with standard triple therapy was reported to be ineffective $(<80 \%)$ in several countries (Chey et al., 2017; Mahachai et al., 2018, Chotivitayatarakorn et al., 2017) due to rising of antibiotic resistant's. New effective regimen might be required to improve treatment of this important bacterium.
Bismuth has long been known to have an antibacterial activity and prevent bacterial colonization to gastric epithelial and has no prior resistance reported to H. pylori. Bismuth has acceptable side effects such as nausea, vomiting, numbness and metallic taste. Another important side effect is a black stool that should be warning not to be from upper GI bleeding (Vilaichone et al., 2006). Currently, bismuth-containing quadruple regimen is promoted to treat $H$. pylori infection as effective first-line regimen in Europe and United States of America (Malfaertheiner et al., 2017, Chey et al., 2017) but limited data in Asia. Our prior study revealed that quadruple therapy had limited efficacy for $H$. pylori treatment in Thailand due to poor compliance, high rate of metronidazole resistance and CYP2C19 genotype RM (Vilaichone et al., 2015), However, this study demonstrated high efficacy of 14-day high-dose PPI- bismuth-containing quadruple therapy with probiotic for H. pylori eradication. Adding probiotic might be improve patient's compliance and high dose PPI could overcome the effect of CYP2C19 genotype that lead this regimen had more effectiveness and better adherence than standard quadruple therapy.

Probiotics are live microorganism that provide benefit

Table 4. Adverse Events Comparing between Probiotics and Without Probiotics Regimens

\begin{tabular}{lcccccc}
\hline Adverse event & $\begin{array}{c}\text { 7-day regimen } \\
\text { + L. reuteri }\end{array}$ & $\begin{array}{c}\text { 7 days regimen } \\
\text { Placebo }\end{array}$ & $\begin{array}{c}\mathrm{P} \\
\text { value }\end{array}$ & $\begin{array}{c}\text { 14-day regimen } \\
\text { + L.reuteri }\end{array}$ & $\begin{array}{c}\text { 14-day regimen } \\
\text { + placebo }\end{array}$ & P value \\
\hline Nausea Vomiting & $12 \%$ & $12 \%$ & 1.0 & $6 \%$ & $26 \%$ & 0.002 \\
Abdominal discomfort & $4 \%$ & $10 \%$ & 0.221 & $4 \%$ & $18 \%$ & 0.017 \\
Diarrhea & 0 & $4 \%$ & 0.149 & 0 & 0 & - \\
Fatique & $6 \%$ & $2 \%$ & 0.297 & $6 \%$ & $8 \%$ & 0.684 \\
Dizziness & $6 \%$ & $6 \%$ & 1.0 & $8 \%$ & $8 \%$ & 1 \\
Bitter taste & $14 \%$ & $12 \%$ & 0.747 & $4 \%$ & $26 \%$ & 0.001 \\
\hline
\end{tabular}


to human health both of digestive tract and immune system. Many studies revealed that probiotics could decrease some adverse effects of the H. pylori treatment regimens (Fuller, 1991; Otles et al., 2003). The possible mechanism of probiotics is restoring the equilibrium of intestinal floras previously altered by the combination of antibiotics in treatment regimen (Armuzzi et al., 2001; Srinarong al., 2014).

L. reuteri is Lactobacilli group which can change gastric environment from lactic acid and 3-hydroxypropionaldehyde (reuterin) production that have antibiotic property against $H$. pylori infection (Dore et al., 2014; Dore et al., 2015). Prior studies of L. reuteri suggested that this organism could reduce side-effects of H. pylori eradication regimen significantly, for example, abdominal pain, bloating and diarrhea (Dore et al., 2014; Dore et al., 2015; Francavilla et al., 2008). Our study also demonstrated that L. reuteri was not only improve eradication rate but also decreased some side effects during treatment especially nausea and vomiting, abdominal discomfort and bitter taste. By decreasing these adverse effects, adding probiotics might increase compliance by helping patients complete eradication regimen.

In conclusion, 14-day High dose PPI- bismuthcontaining quadruple therapy plus L. reuteri provide high cure rate of H.pylori infection in Thai patients with non-ulcer dyspepsia regardless of CYP2C19 and antibiotic resistance pattern. Adding probiotics also decreased side effects during the treatment.

\section{Acknowledgments}

This study was partially supported by the Research Funds of Faculty of Medicine, Thammasat University, Bualuang ASEAN Chair Professorship at Thammasat University, Thailand and Digestive Diseases Research Center(DRC), Thammasat University Hospital, Thailand.

\section{References}

Aumpan N, Vilaichone RK, Chotivitayatarakorn P, et al (2019). High efficacy of rapid urine test for diagnosis of Helicobacter pylori infection in Thai people. Asian Pac Cancer Prev, 20, 1525-9.

Bayerdorffer E, Neubauer A, Rudolph B, et al (1995). Regression of primary gastric lymphoma of mucosa-associated lymphoid tissue type after cure of Helicobacter pylori infection. MALT lymphoma study group. Lancet, $\mathbf{3 4 5}$, 1591-4.

Chey WD, Leontiadis GI, Howden CW, et al (2017). ACG Clinical Guideline: Treatment of Helicobacter pylori Infection. Am J Gastroenterol, 112, 212-39.

Chotivitayatarakorn P, Mahachai V, Vilaichone RK (2017). Effectiveness of 7-day and 14-day MoxifloxacinDexlansoprazole based triple therapy and probiotic supplement for Helicobacter pylori eradication in Thai patients with non-ulcer dyspepsia: A double- blind randomized placebo-controlled study. Asian Pac J Cancer Prev, 18, 2839-43.

de Boer WA, Tytgat GN (1995). The best therapy for Helicobacter pylori infection: should efficacy or side-effect profile determine our choice?. Scand J Gastroenterol, 30, 401-7.

Dore MP, Cuccu M, Pes GM, et al (2014). Lactobacillus reuteri in the treatment of Helicobacter pylori infection. Intern Emerg Med, 9, 649-54.

Dore MP, Goni E, Di Mario F (2015). Is there a role for probiotics in Helicobacter pylori therapy?. Gastroenterol Clin North Am, 44, 565-75.

Ford AC, Forman D, Hunt RH, et al (2014). Helicobacter pylori eradication therapy to prevent gastric cancer in healthy asymptomatic infected individuals: systematic review and meta- analysis of randomised controlled trials. $B M J, 348$, g3174.

Francavilla R, Lionetti E, Castellaneta SP, et al (2008). Inhibition of Helicobacter pylori infection in humans by Lactobacillus reuteri ATCC 55730 and effect on eradication therapy: a pilot study. Helicobacter, 13, 127-34.

Fuller R (1991). Probiotics in human medicine. Gut, 32, 439-42.

Gerrits MM, van Vliet AH, Kuipers EJ, et al (2006). Helicobacter pylori and antimicrobial resistance: molecular mechanisms and clinical implications. Lancet Infect Dis, 6, 699-709.

Graham DY, Lu H, Yamaoka Y (2007). A report card to grade Helicobacter pylori therapy. Helicobacter, 12, 275-8.

Mahachai V, Vilaichone RK, Pittayanon R, et al (2018). H. pylori Management in ASEAN: the Bangkok Consensus Report. $J$ Gastroenterol Hepatol, 33, 37-56.

Mahachai V, Vilaichone RK, Pittayanon R, et al (2016). Thailand consensus on Helicobacter pylori Treatment 2015. Asian Pac J Cancer Prev, 17, 2351-60.

Mahachai V, Sirimontaporn N, Tumwasorn S, et al (2011). Sequential therapy in clarithromycin- sensitive and -resistant Helicobacter pylori based on polymerase chain reaction molecular test. $J$ Gastroenterol Hepatol, 26, 825-8.

Malfertheiner P, Megraud F, O'Morain CA, et al (2017). Management of Helicobacter pylori infection-the Maastricht V/Florence Consensus Report. Gut, 66, 6-30.

Otles S, Cagindi O, Akcicek E (2003). Probiotics and health. Asian Pac J Cancer Prev, 4, 369-72.

Parsonnet J, Friedman GD, Vandersteen DP, et al (1991). Helicobacter pylori infection and the risk of gastric carcinoma. N Engl J Med, 325, 1127-31.

Rahman R, Asombang AW, Ibdah JA (2014). Characteristics of gastric cancer in Asia. World J Gastroenterol, 20, 4483-90.

Rauws EA, Tytgat GN (1990). Cure of duodenal ulcer associated with eradication of Helicobacter pylori. Lancet, 335, 1233-5.

Sheu BS, Cheng HC, Kao AW, et al (2006). Pretreatment with Lactobacillus- and Bifidobacterium-containing yogurt can improve the efficacy of quadruple therapy in eradicating residual Helicobacter pylori infection after failed triple therapy. Am J Clin Nutr, 83, 864-9.

Srinarong C, Siramolpiwat S, Wongcha-um A, et al (2014). Improved eradication rate of standard triple therapy by adding bismuth and probiotic supplement for Helicobacter pylori treatment in Thailand. Asian Pac Cancer Prev, 15, 9909-13.

van der Hulst RW, Keller JJ, Rauws EA, et al (1996). Treatment of Helicobacter pylori infection: a review of the world literature. Helicobacter, 1, 6-19.

Vilaichone RK, Mahachai V (2001). Current management of Helicobacter pylori infection. J Med Assoc Thai, 84, 32-8.

Vilaichone RK, Prapitpaiboon H, Gamnarai P, et al (2015). Seven-day Bismuth-based Quadruple therapy as an initial treatment for Helicobacter pylori infection in a high metronidazole resistant area. Asian Pac J Cancer Prev, 16, 6089-92.

Vilaichone RK, Mahachai V, Graham DY (2006). Helicobacter pylori diagnosis and management. Gastroenterol Clin North Am, 35, 229-47.

Vilaichone RK, Quach DT, Yamaoka Y, et al (2018). Prevalence 
Piyakorn Poonyam et al

and pattern of antibiotic resistant strains of Helicobacter pylori infection in ASEAN. Asian Pac J Cancer Prev, 19, 1411-3.

\section{(ब) $(0 \otimes$}

This work is licensed under a Creative Commons AttributionNon Commercial 4.0 International License. 